\title{
FECUNDITY OF WILD AND LABORATORY REARED ECOTYPES OF MICROCTONUS HYPERODAE LOAN (HYMENOPTERA: BRACONIDAE)
}

\author{
C.B. PHILLIPS ${ }^{1}$, G.M. BARKER ${ }^{2}$, R.L. ROBERTS ${ }^{3}$, \\ M.R. MCNEILL ${ }^{1}$ and S.L. GOLDSON ${ }^{1}$
}

\author{
New Zealand Pastoral Agriculture Research Institute Ltd, \\ ${ }^{1}$ Canterbury Agriculture and Science Centre, PO Box 60, Lincoln \\ ${ }^{2}$ Ruakura Agricultural Research Centre, Private Bag 3123, Hamilton \\ ${ }^{3}$ Department of Plant and Microbial Sciences, Canterbury University, \\ Private Bag 4800, Christchurch
}

\begin{abstract}
Microctonus hyperodae Loan (Hymenoptera: Braconidae) is a biological control agent of the pasture pest Argentine stem weevil (Listronotus bonariensis (Kuschel) (Coleoptera: Curculionidae)). Two experiments compared the fecundity of laboratory reared $M$. hyperodae of known ecotypes to that of field collected parasitoids of unknown ecotype(s). In both experiments, the fecundity of field collected parasitoids was significantly lower than that of the laboratory reared conspecifics, probably due to differences in the ecotypic composition of laboratory reared and field collected parasitoids. Total fecundity of individual parasitoids was strongly correlated to their fecundity during their first 24-48 hours exposure to L. bonariensis. This observation indicated that there is potential to develop much less time consuming methods for measuring the fecundity of the various $M$. hyperodae ecotypes released in New Zealand.
\end{abstract}

Keywords: Listronotus bonariensis, Microctonus hyperodae, ecotypes, fecundity, biological control

\section{INTRODUCTION}

Argentine stem weevil, Listronotus bonariensis (Kuschel) (Coleoptera: Curculionidae) has become well known as a major pasture pest in New Zealand (Prestidge et al. 1991). A parthenogenetic parasitoid, Microctonus hyperodae Loan (Hymenoptera: Braconidae), has recently been established throughout New Zealand as a biological control agent of L. bonariensis (Goldsonet al. 1994). The M. hyperodae adult oviposits in an adult $L$. bonariensis, whereupon a solitary parasitoid larva develops within the living host until maturity. The mature larva then emerges to pupate, while the host dies as a result of the parasitism. Parasitoids released in New Zealand were derived from eight diverse South American locations in Argentina (Ascasubi, Mendoza, General Roca and S. C. de Bariloche), Brazil (Porto Alegre), Chile (Concepcion and La Serena) and Uruguay (Colonia) (Goldson et al. 1990). Released populations comprised approximately equal numbers of $M$. hyperodae derived from each South American geographic population, hereafter called 'ecotypes', to ensure the widest possible range of genetic material was liberated at each site (Goldson et al. 1990). Since the species' importation in 1989-90, M. hyperodae from each ecotype have been maintained in culture to provide genetic stock for further field releases and to supply parasitoids of known ecotype for research purposes (Goldson et al. 1994).

This contribution reports two experiments which compared the vigour of M. hyperodae collected from the field to those reared in the laboratory. The first experiment compared the fecundity and longevity of two laboratory reared M. hyperodae ecotypes to that of parasitoids recovered from the field in 1993 at 
Hamilton. The second compared the fecundity of one laboratory reared $M$. hyperodae ecotype to that of parasitoids collected from the field in 1995 at Lincoln. Although 'wild' $M$. hyperodae were compared to only 1-2 laboratory reared ecotypes, the fecundity and longevity of four $M$. hyperodae ecotypes representing the biogeographical extremes of the ecotypes collected have already been measured (Goldson et al. 1996). It was, therefore, assumed that M. hyperodae's fecundity and longevity had been broadly defined and that major departures from these general parameters by either wild or laboratory reared insects would indicate the occurrence of a stressor such as disease.

\section{Collection of wild $M$. hyperodae}

\section{METHODS}

L. bonariensis adults were collected by vacuuming pasture at Ruakura Agricultural Research Centre, Hamilton on 11 February 1993 and from AgResearch Farm, Lincoln on 14 November 1995. Approximately 150 L. bonariensis were collected at each site and placed in holding cages containing ryegrass (Lolium multiflorum Lam.). Holding cages comprised two circular chambers, $100 \mathrm{~mm}$ diameter $\times 70 \mathrm{~mm}$, stacked one upon the other. The upper chamber had a $0.5 \times 0.5 \mathrm{~mm}$ mesh floor that allowed emergent parasitoid prepupae to drop through the mesh and pupate under paper strips placed in the lower chamber. Pupae were then transferred to Petri dishes until eclosion; thereafter newly eclosed adult parasitoids were selected randomly for use in the experiments.

\section{Laboratory reared $M$. hyperodae}

Laboratory reared parasitoids used in the Hamilton experiment were derived from Colonia and General Roca, while those used in the Lincoln experiment were derived from Ascasubi.

\section{M. hyperodae oviposition}

In the Hamilton experiment, parasitoids which had eclosed less than 1 hour earlier were placed for 1 hour in $55 \times 20 \mathrm{~mm}$ diameter glass vials containing filter paper (10 $\mathrm{x} 10 \mathrm{~mm}$ ) soaked in 50:50 honey:water solution. After this, parasitoid oviposition was measured in $100 \mathrm{~mm}$ diameter $\mathrm{x} 75 \mathrm{~mm}$ gauze-covered cages (exposure cages). Each exposure cage contained one parasitoid, 30 weevils and a bouquet of $L$. multiflorum (cultivar 'Concord'). Exposure cages were held at ambient room temperature (mean ca. $18^{\circ} \mathrm{C}$ ) and day length. Every 24 hours, parasitoids were removed from exposure cages and placed in vials containing paper soaked in 50:50 honey:water solution. After 30 minutes, parasitoids were transferred to new cages, each with 30 fresh, unparasitised L. bonariensis. This procedure was repeated until the parasitoids died.

In the Lincoln experiment, parasitoid oviposition was measured in $220 \times 135 \times 75$ $\mathrm{mm}$ exposure cages. All parasitoids were <48 hours old at the experiment's commencement. Each cage contained one parasitoid, either 10 or 20 weevils (explained below) and a bouquet of L. multiflorum (cultivar 'Tama'). Exposure cages were held at $25^{\circ} \mathrm{C}, 14: 10$ light:dark. The experiment was conducted over 10 consecutive days. Every 24 hours, parasitoid-exposed weevils were removed and replaced with fresh, unexposed weevils. Twenty weevils were allocated to each exposure cage for the first three 24 hour periods. From the fourth day onwards, each parasitoid was exposed to 10 weevils per 24 hours. Filter paper $(10 \times 10 \mathrm{~mm})$ soaked in 50:50 honey:water solution was placed on the gauze lid of the exposure cages as food for $M$. hyperodae adults and was renewed every 24 hours.

In both experiments, parasitoid-exposed weevils were kept in cages for 9-10 days with L. multiflorum to allow newly-laid parasitoids to develop to first instar so that they could be found readily during weevil dissections. During the 9-10 day maintenance period, weevils were checked every 48 hours and cadavers removed and dissected to ascertain the presence of parasitoid eggs.

In the Hamilton experiment, fecundity on each day of the parasitoids' lifespans was estimated by dissecting all exposed weevils and counting the number of immature parasitoids. In the Lincoln experiment, fecundity was estimated for 10 wild and 10 laboratory reared parasitoids which had survived the 10 day duration of the experiment. Weevils which had been exposed to these parasitoids on days 1, 2, 3, 5 and 9 were dissected. The parasitoids' total fecundity was not, therefore, measured. Instead, 
oviposition by each parasitoid which occurred during five (of a total of 10) 24 hour exposure periods was recorded.

\section{Statistical analyses}

Egg count data were fitted to a generalised linear model with Poisson errors and compared by analysis of deviance using the Chi-square distribution for probability estimates (Green and Silverman 1994). Egg laying curves were fitted by regression with Poisson errors (Green and Silverman 1994). The longevity data from the Hamilton experiment were assessed by analysis of variance.

\section{Hamilton experiment}

\section{RESULTS}

There was significant curvature in the relationship between egg counts and days, so a cubic spline regression was used to describe the relationship between egg laying and days (Fig. 1) (Green and Silverman 1994). Analysis of deviance showed that egg counts varied significantly with day $(\mathrm{P}<0.005)$, declining rapidly from about 10 eggs per parasitoid on day 2 to approximately zero eggs on day 14 (Fig. 1). The decline in egg laying occurred at similar rates for parasitoids from Colonia, General Roca and Hamilton (Fig. 1). Analysis of deviance indicated that the total fecundity of Hamilton parasitoids was significantly less than that of the Colonia ecotype $(\mathrm{P}<0.005)$ (Table 1$)$.

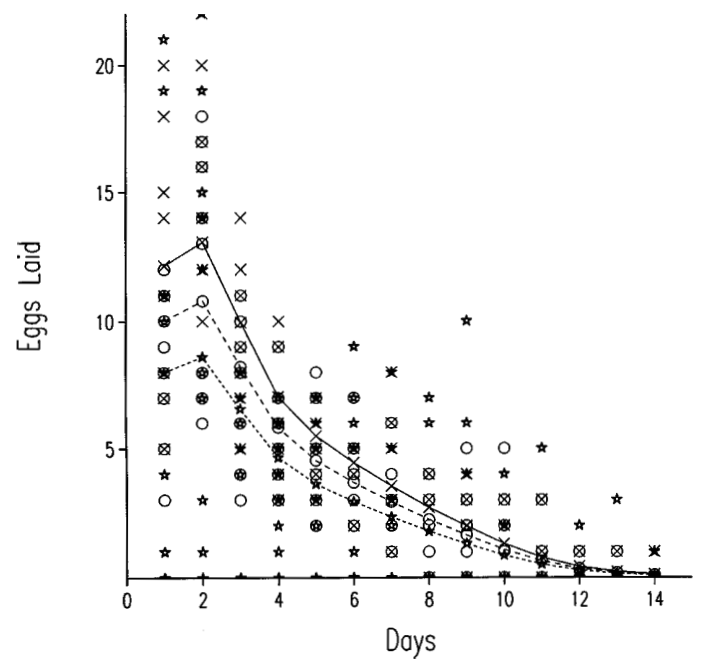

FIGURE 1: Graph of eggs laid per day forMicroctonus hyperodae derived from Hamilton ( $\star$; lower regression line), Colonia $(X$; upper regression line) and General Roca $(\bigcirc$; middle regression line).

The Hamilton, Colonia and General Roca populations had mean longevities $( \pm$ $95 \%$ confidence intervals) of $7.7 \pm 2.1,9.9 \pm 2.3$ and $9.9 \pm 1.7$ days respectively; the variation in longevity between wild and laboratory reared $M$. hyperodae was almost significant $(\mathrm{P}=0.06)$. By day $7,50 \%$ of wild parasitoids had died, while $100 \%$ of parasitoids from both laboratory reared ecotypes were still alive (Fig. 2). The strong tendency for reduced survival of wild parasitoids was apparent until about day 13 when percent survival of wild as well as laboratory reared $M$. hyperodae populations became similarly low (Fig. 2).

1995 Lincoln experiment

There was no significant curvature in the relationship between egg counts and days, so a linear term for days was used to model the relationship between egg laying 


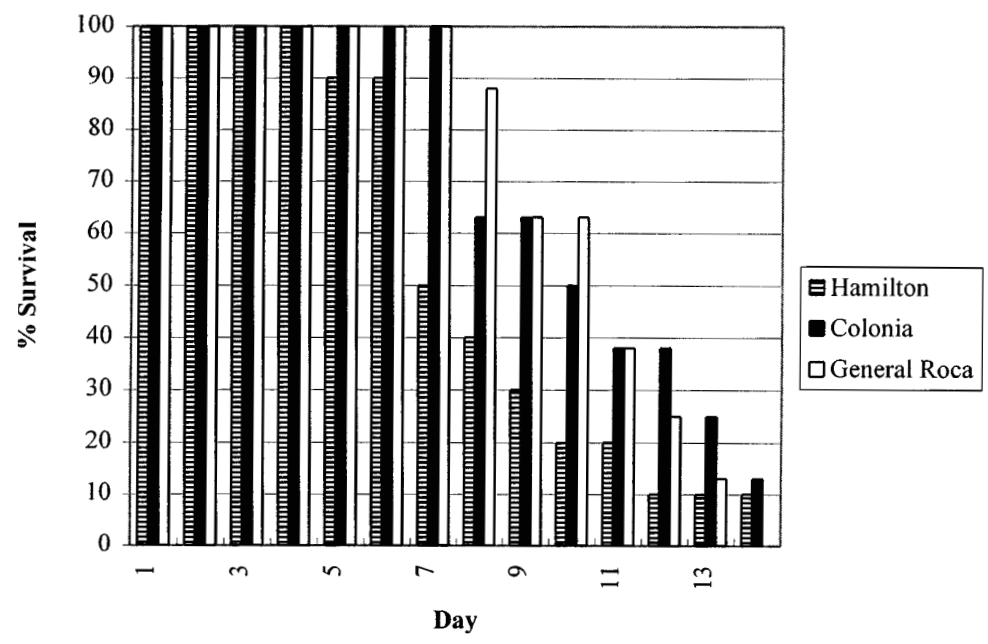

FIGURE 2: Percent survival versus day for wild (Hamilton) and laboratory reared (Colonia and General Roca) Microctonus hyperodae adults.

and days (Fig. 3) (Green and Silverman 1994). Analysis of deviance showed that egg counts varied significantly with day $(\mathrm{P}<0.005)$, whereby egg counts declined rapidly from about 15 eggs per parasitoid on day 1 to approximately two eggs on day 9 (Fig. 3). Maximum oviposition occurred for $90 \%$ of $M$. hyperodae within the first 24 hour exposure period (i.e., when parasitoids were less than 72 hours old) (Fig. 3). The decline in egg laying occurred at similar rates for parasitoids from Ascasubi and

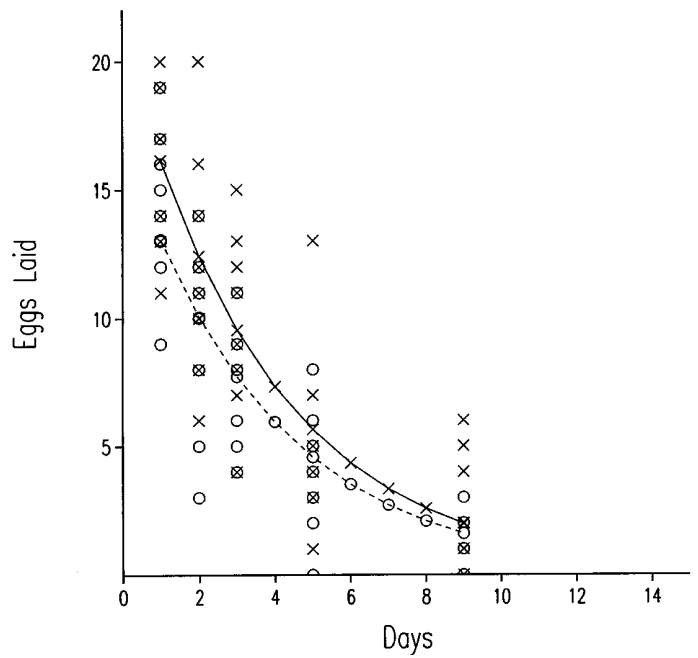

FIGURE 3: Graph of number of eggs laid per day for Microctonus hyperodae derived from the field at $\operatorname{Lincoln}(\bigcirc$; lower regression line) and the laboratory reared Ascasubi ecotype (X; upper regression line). Data of parasitoids which died prior to day ten excluded. 
Lincoln (Fig. 3). Analysis of deviance indicated that total fecundity varied significantly between parasitoids derived from different populations. Wild parasitoids collected at Lincoln were least fecund (Table 1), while laboratory reared parasitoids from Ascasubi were most fecund $(\mathrm{P}<0.005)$ (Table 1$)$.

TABLE 1: Mean number of Microctonus hyperodae eggs laid per 24 hours on days 1, 2, 3, 5 and 9 and mean total eggs laid during the five 24 hour exposure periods and total fecundity ( $n$ is the number of parasitoid females). Data of Goldson et al. (1996) for parasitoids derived from four South American locations are also presented.

\begin{tabular}{ccccccccc}
\hline Ecotype & $\mathrm{n}$ & Day & Day & Day & Day & Day & 5 -Day & Total \\
& & 1 & 2 & 3 & 5 & 9 & Fecundity & Fecundity \\
\hline
\end{tabular}

1993 Hamilton Experiment

$\begin{array}{lcrrrrrrl}\text { Hamilton }^{1} & 10 & 6.6 & 10.1 & 5.5 & 4.2 & 2.0 & 28 & 42 \pm 22^{2} \\ \text { Colonia } & 8 & 12.3 & 16.0 & 9.7 & 5.4 & 1.6 & 45 & 63 \pm 15 \\ \text { General Roca } & 8 & 8.4 & 12.4 & 7.8 & 4.3 & 1.8 & 35 & 52 \pm 12\end{array}$

1995 Lincoln Experiment

\begin{tabular}{lrrrrrrrl} 
Lincoln $^{1}$ & 10 & 14.5 & 9.5 & 7.9 & 4.1 & 1.0 & $37 \pm 6$ & - \\
Ascasubi & 10 & 15.5 & 12.5 & 9.5 & 5.1 & 3.1 & $46 \pm 8$ & - \\
\multicolumn{2}{l}{} & & & & & & & \\
Data of Goldson & et & al. $(1996)$ & & & & & & \\
Colonia & 9 & 12.1 & 9.8 & 6 & 6.4 & 3.1 & $38 \pm 8$ & $62 \pm 15$ \\
La Serena & 7 & 8.4 & 8.4 & 5.3 & 4.7 & 0.5 & $27 \pm 5$ & $43 \pm 8$ \\
Porto Alegre & 4 & 10.1 & 2.5 & 2.6 & 2.6 & 0.8 & $19 \pm 15$ & $32 \pm 29$ \\
S. C. de Bariloche & 4 & 8.8 & 8.5 & 6.7 & 2.7 & 1.6 & $28 \pm 5$ & $41 \pm 13$ \\
\hline
\end{tabular}

${ }^{1}$ wild parasitoids

$295 \%$ confidence interval

\section{DISCUSSION}

The fecundity of the Hamilton population collected in 1993 was significantly lower than that of the Colonia ecotype, and tended to be lower than that of the General Roca ecotype. Although the methods used in the Hamilton experiment differed from those of Goldson et al. (1996), cautious comparison indicated that the Hamilton parasitoids had fecundities within the range measured by Goldsonet al. (1996) (Table 1). Validity of the comparisons between these experiments is supported by the observed similarity in total fecundity for the Colonia ecotype (63 c.f. 62; Table 1). The fecundity of the Hamilton population appeared similar to the La Serena and S. C. de Bariloche ecotypes as measured by Goldson et al. (1996) (Table 1). The strong tendency for reduced longevity amongst the Hamilton population is difficult to explain and may warrant further investigation.

The five-day fecundity of the Lincoln population was significantly less than that of the laboratory reared ecotype (Ascasubi) to which it was compared (Table 1). This difference between wild and laboratory reared parasitoids, however, was not as great as that observed in the Hamilton experiment (Table 1). Mean fecundities were biased towards high values in the Lincoln experiment because, unlike the Hamilton and Goldson et al. (1996) experiments, parasitoids which died before 10 days egg laying had occurred were excluded from the analysis. Even when allowing for this bias, however, the wild Lincoln parasitoids appeared to have fecundities which lay generally within the range measured by Goldson et al. (1996) (Table 1). As in the Hamilton experiment, therefore, it is probable that the difference in fecundity between the Lincoln and Ascasubi populations was not due to the presence of disease, but because the ecotypic composition of the wild parasitoids differed from that of the insects to which they were compared. 
Wild and laboratory reared parasitoids in both the Hamilton and Lincoln experiments exhibited temporal patterns of oviposition broadly similar to that reported by Goldson et al. (1996) (Table 1). Peak oviposition occurred early in the parasitoid's life span (<ca. 48 hours) in all experiments. The observation that parasitoids in the 1993 Hamilton experiment displayed peak oviposition on day 2, while the Lincoln 1995 experiment and Goldson et al. (1996) noted peak oviposition on day 1 (Table 1), can be explained by a difference in experimental methods. The Hamilton 1993 experiment used parasitoids which were less than 2 hours old, while the Lincoln 1995 and Goldson et al. (1996) experiments used M. hyperodae which were less than 48 and 24 hours old respectively. It appears, therefore, that $M$. hyperodae may not reach its maximum egg laying potential until it is approximately 24 hours old.

In general, after 48 hours egg laying, daily oviposition by all $M$. hyperodae ecotypes declined at broadly similar rates, irrespective of the number of eggs laid in the first 48 hours (Figs. 1, 3). In other words, parasitoids which laid more eggs than average in the first 48 hours showed a strong tendency to have higher than average total fecundities and vice versa. This observation is of considerable interest because it suggests that the relative fecundities of $M$. hyperodae ecotypes could be ascertained very efficiently by measuring egg laying in only the first 48 hours. This may assist research into the fecundity of the $M$. hyperodae ecotypes from Mendoza and Concepcion which have also been released in New Zealand (Goldson et al. 1990), as well as work required to standardise the various fecundity measurements made to date.

\section{ACKNOWLEDGEMENTS}

Thanks to Dr D. Baird who assisted with statistics, and to Mr H. Macnab, Mr J. Proffitt (AgResearch, Lincoln) and Mr P. Addison (AgResearch, Ruakura) for their ideas and assistance generally. Dr A. Popay and Dr M. O'Callaghan provided valuable editorial comment on an earlier draft of this manuscript.

\section{REFERENCES}

Goldson, S.L., McNeill, M.R., Stufkens, M.W., Proffitt, J.R. and Farrell, J.A., 1990. Importation and quarantine ofMicroctonus hyperodae a South American parasitoid of Argentine stem weevil.Proc. 43rd N.Z. Weed and Pest Control Conf.:334-338.

Goldson, S.L., Barker, G.M. and Barratt, B.I.P., 1994. The establishment of an Argentine stem weevil parasitoid at its release sites. Proc. 47th N.Z. Plant Prot. Conf: :274-276.

Goldson, S.L., McNeill, M.R., Proffitt, J.R. and Hower, A.A., 1996. An investigation into the reproductive characteristics of Microctonus hyperodae Loan (Hymenoptera: Braconidae), a parasitoid of Listronotus bonariensis (Kuschel) (Coleoptera: Curculionidae). Biocon. Sci. Tech.: in press.

Green, P. and Siverman, B., 1994. Nonparametric regression and generalized linear models. London: Chapman \& Hall.

Prestidge, R.A., Barker, G.M. and Pottinger, R.P., 1991. The economic cost of Argentine stem weevil in pastures in New Zealand.Proc. 44th N.Z. Weed and Pest Control Conf: : 165-170. 